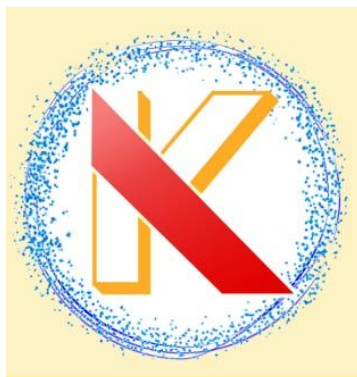

\title{
Sintesis Nanopartikel Perak Menggunakan Ekstrak Daun Eceng Gondok (Eichornia crassipes) Sebagai Bioreduktor
}

\section{[Synthesis of Silver Nanoparticles Using Leaves Extract of Water Hyacinth (Eichornia crassipes) As a Bioreductor]}

\author{
Syahruddin Kasim ${ }^{1^{\star}}$, Paulina Taba ${ }^{1}$, Ruslan $^{2}$, Romianto $^{1}$ \\ ${ }^{1)}$ Departemen kimia, Fakultas Matematika dan Ilmu Pengetahuan Alam, Universitas Hasanuddin, 90111 , \\ Makassar, Sulawesi selatan, Indonesia.
2) Jurusan Kimia, Fakultas Matematika dan IImu Pengetahuan Alam,Universitas Tadulako, Jl. Soekarno-Hatta \\ Km.9, Palu, Sulawesi Tengah \\ *)Corresponding Author: kasimsyahruddin@gmail.com
}

\begin{abstract}
Nanoparticles was done by adding water hyacinth leave extract to $\mathrm{AgNO}_{3} 2 \mathrm{mM}$ solution with ratio of 1:40. Formed silver nanoparticles were analyzed using UV-Vis spectrophotometer, SEM, XRD, PSA, and FTIR to determine its characteristics. Results showed that absorbance value increased if reaction time is increased. Maximum absorption was obtained at wavelength $432-446 \mathrm{~nm}$ by using UV-Vis spectrophotometer. Result of PSA analysis shows that the average size of silver nanoparticles formed is $93.2 \mathrm{~nm}$ while XRD analysis shows that the average crystal size of silver nanoparticles is $50.11 \mathrm{~nm}$, with round shape and amorphous. Result of FTIR analysis to determine functional group that contributes in nanoparticle synthesis shows the contribution of $\mathrm{OH}$ group.
\end{abstract}

Keywords: reduction method, silver nanoparticles, Eichornia crassipes, bioreductor

Abstrak. Nanopartikel perak telah disintesis dengan metode reduksi menggunakan ekstrak daun eceng gondok (Eichornia crassipes) sebagai bioreduktor. Proses pembentukan nanopartikel perak dilakukan dengan penambahan ekstrak daun eceng gondok kedalam larutan $\mathrm{AgNO}_{3} 2 \mathrm{mM}$ dangan perbandingan 1:40. Analisis spektrofotometer UV-Vis, SEM, XRD, PSA dan FTIR digunakan untuk mengkarakterisasi nanopartikel perak yang dihasilkan. Hasil penelitian menunjukkan bahwa nilai absorbansi meningkat dengan meningkatnya waktu kontak reaksi. Serapan maksimum diperoleh pada panjang gelombang $432-446 \mathrm{~nm}$ dengan menggunakan spektrofotometer UV-Vis. Ukuran rata-rata nanopartikel perak berdasarkan hasil analisis PSA adalah 93,2 nm, ukuran kristal nanopartikel perak di tentukan menggunakan XRD dengan ukuran rata-rata 50,11 nm, nanopartikel perak berbentuk bulat tidak seragam. Analisis gugus fungsi yang berperan dalam sintesis nanopartikel menggunakan FTIR menunjukkan adanya kontribusi gugus $\mathrm{OH}$.

Kata Kunci : metode reduksi, nanopartikel perak, Eichornia crassipes, bioreduktor

Riwayat artikel: Diterima 15 Mei 2020, Disetujui 22 Agustus 2020

Cara sitasi: Kasim, S., Taba, S., Ruslan., \& Romianto. (2020). Sintesis Nanopartikel Perak Menggunakan Ekstrak Daun Eceng Gondok (Eichornia crassipes) Sebagai Bioreduktor. KOVALEN: Jurnal Riset Kimia, 6(2): 126-133.

DOI: https://doi.org/10.22487/kovalen.2020.v6.i2.15137

\section{LATAR BELAKANG}

Nanopartikel merupakan suatu teknologi desain dan pemafaatan struktur material yang berdimensi nanometer. Nanopartikel tidak sekedar diartikan sebagai partikel yang berukuran nanometer, tetapi dapat hingga 
pembahasan mengenai bagaimana metode pembuatan dan mengkaji kegunaan sifat baru dari material nano yang telah disintesis. Material nanopartikel yang banyak dimanfaatkan pada bidang indutri ialah yang memiliki ukuran 1-100 nm. Modifikasi material skala nanometer bertujuan untuk menciptakan materi yang memiliki ukuran, struktur, dan sifat yang lebih efektif dan efisien (Ariyanta, 2016).

Proses sintesis nanopartikel dapat berlangsung dalam fasa cair, padat, dan gas. Proses pembuatan dapat terjadi secara kimia maupun fisika. Pada sintesis secara fisika hanya terjadi pemecahan material besar menjadi material sangat kecil (ukuran nanometer) tanpa mengubah sifat bahan. Proses sintesis secara kimia, terjadi reaksi kimia dari sejumlah material awal. Pembentukan nanopartikel dengan keteraturan yang tinggi dapat menghasilkan pola yang lebih seragam dan ukuran yang seragam (Abdullah et al., 2008).

Secara garis besar sintesis nanopartikel dilakukan dengan metode top-down (fisika) dan metode botton-up (kimia) (Abdullah et al., 2008). Namun, penerapan kedua metode ini memerlukan biaya yang cukup besar dan menimbulakn resiko terhadap lingkungan. Biosintesis nanopartikel perak dengan menggunakan ekstrak tanaman merupakan salah satu metode yang efektif (Chandran et al., 2006; Leela \& Vivekanandan, 2008). Nanopartikel perak dapat menjadi alternatif produksi karena metode ini dapat meminimalisir penggunaan bahan-bahan yang berbahaya dari limbah yang dihasilkan (Yanti \& Astuti, 2018).

Senyawa bioaktif yang terkandung pada tumbuhan seperti senyawa antioksidan dan senyawa metabolit sekunder tertentu, seperti kelompok senyawa terpenoid dan flavonoid yang diduga berperan dalam proses reduksi ion logam (Marlinda et al., 2016; Masakke et al., 2015). Berbagai jenis kelompok tanaman yang mengandung metabolit sekunder seperti yang telah di tuliskan diatas, salah satunya eceng gondok.

Eceng gondok merupakan tumbuhan yang mengambang di permukaan air (gulma) (Mustari et al., 2017). Eceng gondok dapat menyebabkan gangguan antara lain adalah dapat menyebar di area yang luas dan menutupi permukaan air, dapat mengurangi cahaya yang masuk ke dalam badan air, yang mengakibatkan berkurangnya kandungan oksigen terlarut yang dalam air. Hasil uji fitokimia yang telah dilakukan ternyata ekstrak tanaman eceng gondok memiliki kandungan metabolit sekunder seperti senyawa alkaloid, komponen fenol, terpenoid dan senyawa flavonoid (Wijaya et al., 2015). Pemanfaatan ekstrak eceng gondok sebagai bioreduktor pada sintesis nanopartikel belum pernah dilakukan, sehingga sangat berpotensi sebagai bioreduktor terbaru dalam sintesis nanopartikel perak.

\section{METODOLOGI PENELITIAN}

\section{Bahan dan Peralatan}

Bahan yang digunakan meliputi eceng gondok, aquabides, aquades, $\mathrm{AgNO}_{3}$ (Merck), kertas saring whatman no.42 dan aluminium foil. Peralatan yang digunakan yaitu magnetic stirrer, Freeze dry, corong, spektrofotometri UV-Vis, FTIR (Fourier Tansform Infrared Spectroscopy) , XRD, PSA (particle size analyzer), timbangan analitik, serta alat yang lasim digunakan di laboratorium.

\section{Prosedur Penelitian}

\section{Preparasi sampel}

Tanaman yang digunakan dalam penelitian ini adalah eceng gondok yang 
diperoleh dari area perintis kemerdekaan, makassar,suawasi selatan. Daun Eceng gondok dicuci hingga bersih dengan aquades dan dikeringkan pada suhu ruang, setelah itu dihaluskan dan ditimbang sebanyak 5 gram. Setelah itu dimasukkan kedalam erlemeyer $250 \mathrm{~mL}$ dan ditambahkan $100 \mathrm{~mL}$ aquabides lalu dipanaskan hingga mendidih. Setelah itu didinginkan pada suhu ruang, air rebusan disaring menggunakan kertas whatman 42. Air rebusan tersebut dapat digunakan langsung untuk proses biosintesis serta air rebusan dapat disimpan dalam lemari pendingin (Yanti \& Astuti, 2018).

Pembuatan larutan $\mathrm{AgNO}_{3}$ (Matutu et al., 2016)

Sebanyak 0,068 gram serbuk $\mathrm{AgNO}_{3}$ dilarutkan ke dalam akuabides hingga volume $250 \mathrm{~mL}$ dan dihomogenkan untuk membuat larutan $\mathrm{AgNO}_{3} 2 \mathrm{mM}$. Selanjutnya dipipet sebanyak $37,5 \mathrm{~mL}, 25 \mathrm{~mL}$ dan $12,5 \mathrm{~mL}$ dari larutan $\mathrm{AgNO}_{3} 2 \mathrm{mM}$ ke dalam labu ukur 50 $\mathrm{mL}$ dan ditambahkan akuabides hingga tanda batas untuk membuat konsentrasi $\mathrm{AgNO}_{3}$ 1,5 $\mathrm{mM}, \quad 1 \mathrm{mM}$ dan $0,5 \mathrm{mM}$.

\section{Optimasi konsentrasi (Taba et al., 2019)}

Larutan $\mathrm{AgNO}_{3} 2 \mathrm{mM} ; 1,5 \mathrm{mM} ; 1 \mathrm{mM}$ dan $0,5 \mathrm{mM}$ dipipet sebanyak $40 \mathrm{~mL}$ dan masingmasing larutan dimasukkan kedalam Erlenmeyer $250 \mathrm{~mL}$, kemudian ditambahkan 1 $\mathrm{mL}$ ekstrak daun eceng gondok. Campuran diaduk dengan magnetik stirer hingga terjadi perubahan warna, kemudian dianalisis menggunakan spektrofotometer UV-Vis.

\section{Optimasi komposisi (Taba et al., 2019)}

Ekstrak daun eceng gondok sebanyak 1 $\mathrm{mL}$ dipipet dan dimasukkaN masing-masing ke dalam 3 erlenmeyer $250 \mathrm{~mL}$, kemudian ditambahkan dengan larutan $\mathrm{AgNO}_{3} 2 \mathrm{mM}$ sebanyak $20 \mathrm{~mL}, 30 \mathrm{~mL}$ dan $40 \mathrm{~mL}$ kedalam masing-masing erlenmeyer. Campuran diaduk dengan pengaduk magnetik hingga terjadi perubahan warna, kemudian dianalisis dengan UV-Vis.

\section{Sintesis nanopartikel}

Larutan $\mathrm{AgNO}_{3}$ sebanyak $40 \mathrm{~mL}$ dicampur dengan $1 \mathrm{~mL}$ ekstrak daun eceng gondok kemudian campuran diaduk menggunakan pengaduk magnetik hingga terjadi perubahan warna dan disimpan dalam botol kaca. Karakteristik larutan diamati dengan perubahan warna, spektrum serapan UV-Vis pada waktu ke 1 hari, 2 hari, 3 hari, 4 hari, 7 hari, dan 8 hari (modifikasi metode Masakke et al., 2015 dan Taba et al., 2019). Setelah mencapai waktu optimum disentrifugasi, kemudian dianalisis dengan PSA. Kemudian dikeringkan pada frezze dry untuk dikarakterisasi XRD, SEM, FTIR.

\section{HASIL DAN PEMBAHASAN}

\section{Hasil Optimasi Konsentrasi}

Larutan $\mathrm{AgNO}_{3}$ dengan variasi konsentrasi $\quad 0,5 \mathrm{mM} ; 1,0 \mathrm{mM} ; 1,5 \mathrm{mM}$; dan 2,0 mM. Spektrum serapan UV-Vis dari nanopartikel perak sebagai fungsi konsentrasi larutan $\mathrm{AgNO}_{3}$ dapat dilihat pada Gambar 1 . Pengukuran absorbansi larutan dilakukan pada kisaran panjang gelombang 200-700 nm menunjukkan bahwa panjang gelombang dan absorbansi dari nanopartikel perak bertambah dengan bertambahnya waktu. Nanopartikel perak dengan variasi konsentrasi larutan $\mathrm{AgNO}_{3}$, menunjukkan semakin kecil konsentrasi larutan $\mathrm{AgNO}_{3}$ yang digunakan maka semakin kecil absorbansi yang terbentuk. Begitu sebaliknya semakin besar konsentrasi larutan $\mathrm{AgNO}_{3}$ yang digunakan maka semakin besar absorbansi yang terbentuk. Dari keempat variasi konsentrasi 
larutan $\mathrm{AgNO}_{3}$ yang memiliki panjang gelombang paling kecil dan absorbansi yang besar adalah konsentrasi 2 mM. Gambar 1 menunjukan konsentrasi larutan $\mathrm{AgNO}_{3}$ yang digunakan untuk sintesis nanopartikel perak.

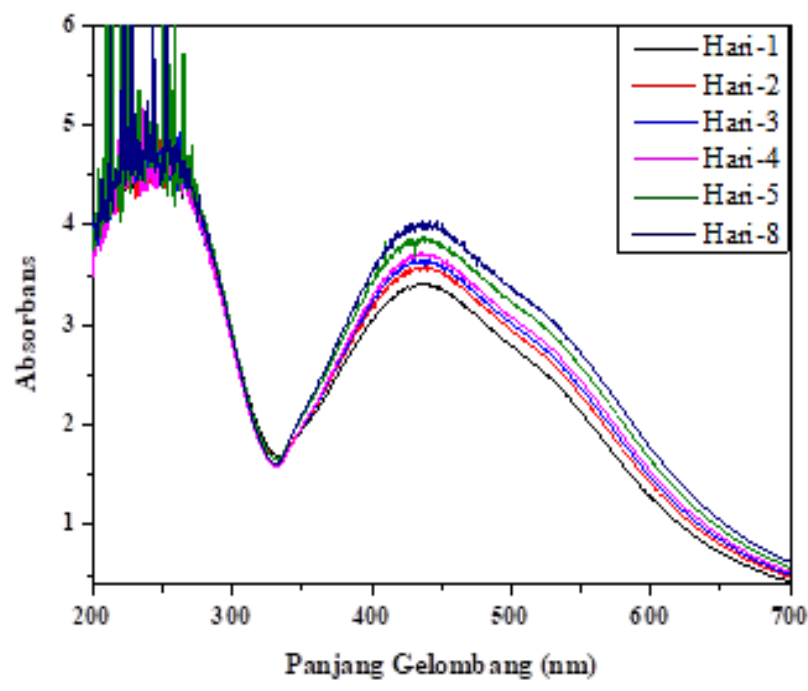

Gambar 1. Optimasi konsentrasi larutan $\mathrm{AgNO}_{3}$

\section{Hasil Optimasi Komposisi}

Perbandingan komposisi larutan $\mathrm{AgNO}_{3} 2$ $\mathrm{mM}$ diperoleh hasil bahwa semakin besar komposisi larutan $\mathrm{AgNO}_{3} 2 \mathrm{mM}$ terhadap ekstrak daun eceng gondok yang digunakan maka semakin kecil panjang gelombang dan absorbansi yang dihasilkan (Tabel 1). Hal yang sama juga dilaporkan oleh Taba et al. (2019) pada nanopartikel perak dengan ekstrak daun salam. Komposisi larutan $\mathrm{AgNO}_{3}$ 2 mM yaitu 1:20 memiliki panjang gelombang dan absorbansi yang besar dibandingkan dengan komposisi 1:30 dan 1:40 yang menunjukkan kemungkinan terjadinya aglomerasi dan membentuk warna kehitaman. Untuk komposisi 1:30 dan 1:40 memiliki panjang gelombang yang sama pada hari ke-1 sehingga komposisi dengan absorbansi yang paling besar (1:40) dipilih untuk sintesis nanopartikel perak dalam jumlah besar. Mekanisme reaksi pembentukan nanopartikel perak dengan senyawa aktif yang tedapat dalam ekstrak daun eceng gondok (Eichornia crassipes) di sajikan pada Gambar 2.

Tabel 1. Optimasi komposisi

\begin{tabular}{ccc}
\hline Komposisi & $\begin{array}{c}\text { Panjang } \\
\text { gelombang }(\mathrm{nm})\end{array}$ & Absorban \\
\hline $1: 20$ & 440,50 & 1,032 \\
$1: 30$ & 439,50 & 1,772 \\
$1: 40$ & 439 & 2,582 \\
\hline
\end{tabular}

\section{Distribusi Ukuran Nanopartikel dengan PSA}

Karakterisasi dengan Particle Size Analyzer (PSA) bertujuan untuk mengetahui distribusi ukuran nanopartikel dengan menggunakan metode uji dynamic lights cattering. Hasil analisis menunjukkan ukuran partikel yang diperoleh berkisar antara 15,6 hingga 76,9 nm dengan diameter rata-rata partikel adalah 93,2 $\mathrm{nm}$. Ukuran yang diperoleh lebih kecil dibandingkan penelitian Masakke et al. (2015) yang menghasilkan nanopartikel perak dengan bioreduktor ekstrak daun manggis berdiameter 339,44 $\mathrm{nm}$. Namun, hasil penelitian ini masih lebih besar dibandingkan ukuran nanopartikel perak dengan daun ekstrak salam Taba et al. (2019), yaitu 45,7 nm. Sementara itu, nilai Polydispersity Index (PI) uang diperoleh adalah 0,296. Semakin mendekati 0 (nol) berarti distribusinya semakin baik dan menunjukkan kestabilan fisik yang baik. Berdasarkan histogram distribusi ukuran, diketahui bahwa partikel dengan kategori nanopartikel memiliki persentase intensitas yang dominan dengan kisaran 49,3\%. Ukuran partikel dengan range $21-40 \mathrm{~nm}$ memiliki intensitas yang paling tinggi dengan persentase $13 \%$. 


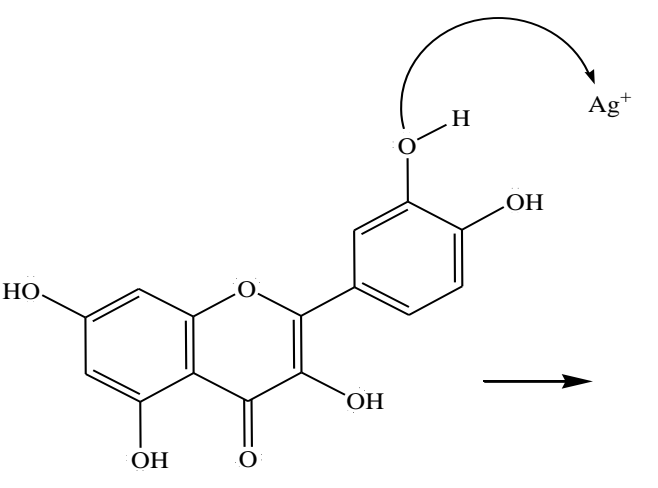

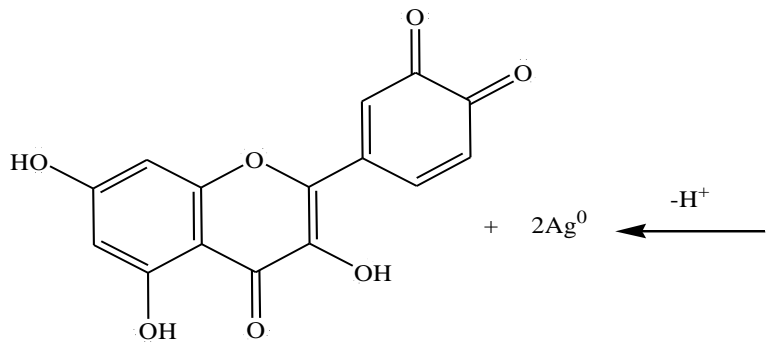<smiles>[12H]Oc1ccc(-c2oc3cc(O)cc(O)c3c(=O)c2O)cc1O</smiles>

Gambar 2. Mekanisme reaksi, pembentukan nanopartikel perak

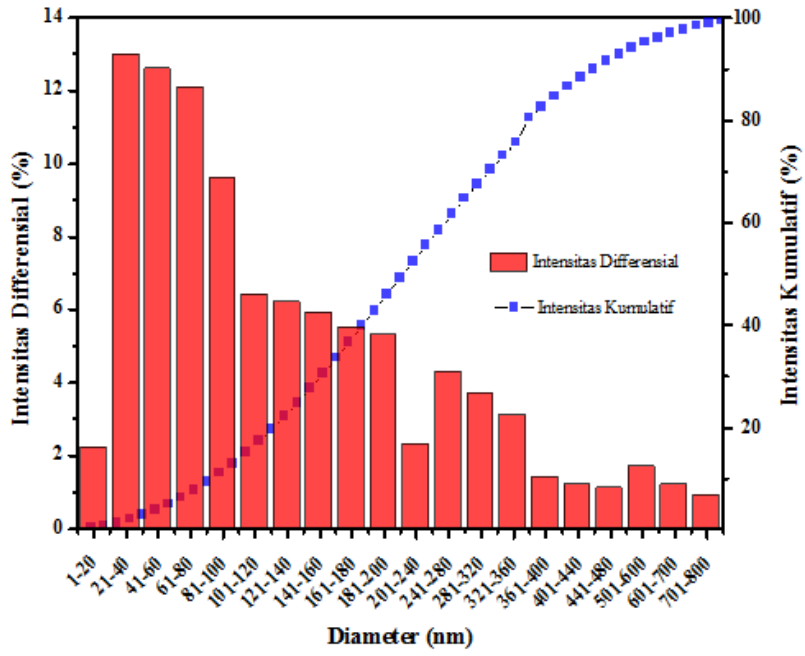

Gambar 3. Histogram distribusi ukuran nanopartikel perak

\section{Spektrum FTIR Nanopartikel Perak}

Analisis dengan FT-IR dilakukan untuk membandingkan gugus fungsi yang terdapat dalam ekstrak air dari Eichornia crassipes dengan nanopartikel perak. Selain itu dapat pula digunakan untuk mengetahui gugus fungsi yang terlibat dalam mereduksi ion $\mathrm{Ag}^{+}$menjadi $\mathrm{Ag}^{\circ}$. Berikut ini adalah perbandingan profil spektrum FT-IR ekstrak air dari Eichornia crassipes dengan nanopartikel perak (Gambar 4).

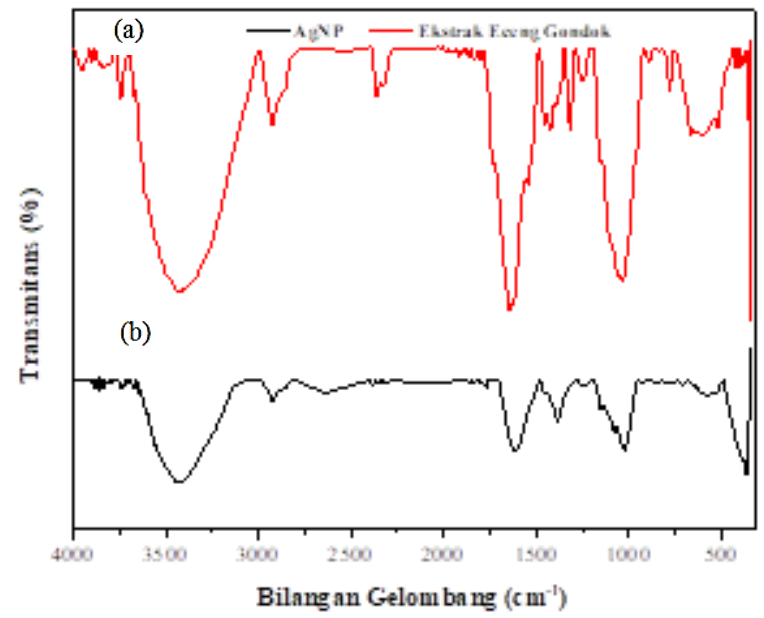

Gambar 4. Spektrum FT-IR (a) ekstrak Eichornia crassipes dan (b) nanopartikel perak 
Tabel 2. Spektrum FT-IR ekstrak Eichornia crassipes dengan nanopartikel perak

\begin{tabular}{ccc}
\hline \multirow{2}{*}{ Gugus Fungsi } & \multicolumn{2}{c}{ Bilangan gelombang $\left(\mathrm{cm}^{-1}\right)$} \\
\cline { 2 - 3 } & $\begin{array}{c}\text { Ekstrak air dari } \\
\text { Eichornia } \\
\text { crassipes }\end{array}$ & $\begin{array}{c}\text { Nanopartikel } \\
\text { perak (AgNPs) }\end{array}$ \\
\hline $\mathrm{O}-\mathrm{H}$ & 3419 & 3442 \\
$\mathrm{C}_{\mathrm{sp} 3}-\mathrm{H}$ & 2924 & 2924 \\
$\mathrm{C}=\mathrm{C}$ aromatik & 1647 dan 1543 & 1612 \\
$-\mathrm{CH}_{3}$ & 1425 dan 1317 & 1454 dan 1384 \\
$\mathrm{C}-\mathrm{O}$ alkohol & 1035 & 1022 \\
Ag-O & - & 364 \\
\hline
\end{tabular}

Ekstrak air dari Eichornia crassipes menunjukkan serapan melebar dengan intensitas yang kuat pada bilangan gelombang $3419 \mathrm{~cm}^{-1}$ menunjukkan adanya vibrasi streching ikatan $\mathrm{O}-\mathrm{H}$ yang berasal dari alkohol atau senyawa fenol. Hal ini diperkuat oleh serapan dengan intesitas kuat pada bilangan gelombang $1035 \mathrm{~cm}^{-1}$ yang merupakan vibrasi streching dari ikatan C-O Alkohol serta serapan pada bilangan gelombang 1647 dan $1543 \mathrm{~cm}^{-1}$ yang menunjukkan adanya vibrasi ikatan $\mathrm{C}=\mathrm{C}$ cincin aromatic (Tabel 2).

Perubahan intensitas serapan pada daerah bilangan gelombang $3419 \mathrm{~cm}^{-1}$ (vibrasi ikatan O$\mathrm{H}), 1647 \mathrm{~cm}^{-1}$ (vibrasi ikatan $\mathrm{C}=\mathrm{C}$ ) dan $1035 \mathrm{~cm}$ 1 (vibrasi ikatan C-O) dapat memberikan petunjuk gugus fungsi yang berperan dalam pembentukan nanopartikel perak. Munculnya serapan pada bilangan gelombang $364 \mathrm{~cm}^{-1}$ pada spektrum FT-IR nanopartikel perak merupakan vibrasi ikatan Ag-O.

\section{Karakteristik Kristal Nanopartikel Perak dengan XRD}

Karakterisasi nanopartikel perak dengan menggunakan XRD dilakukan untuk mengetahui karakteristik kristal nanopartikel perak yang telah disintesis.

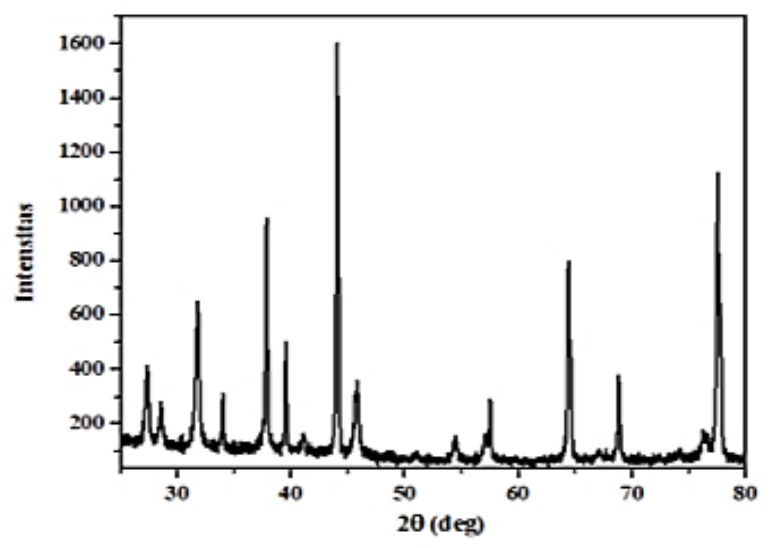

Gambar 5. Difraktogram nanopartikel perak dengan bioreduktor ekstrak Eichornia crassipes

Difraktogram nanopartikel perak menunjukkan puncak pada sudut difraksi (2Ө) yang memiliki kesesuain terhadap data difraksi standard $\mathrm{Ag}$ yang diterbitkan dalam data Joint Committee on Powder Diffraction Standards (JCPDS, file No. 87-0720) adalah 37,83, 44,07, 64,44 dan 77,55 (Gambar 5, Tabel 3). Namun dari hasil difragtogram menunjukan adanya peak yang tidak sesuai dengan data Standar Ag, menandakan adanya partikel-partikel pengotor. Hasil analisis secara teoritik terhadap masingmasing puncak difraksi tersebut menunjukkan indeks Miller pada masing-masing puncak difraksi adalah $\{111\}\{200\}\{220\}$ dan $\{311\}$, indeks Miller merupakan bidang kisi kristal (hkl) yang menyatakan sistem kristal suatu material.

Dari difraktogram terdapat puncak selain puncak khas nanopartikel perak, hal ini menandakan bahwa nanopartikel perak yang dihasilkan masih mengandung pengotor atau belum murni $100 \%$ nanopartikel perak. 
Tabel 3. Hasil analisis ukuran kristal nanopartikel perak

\begin{tabular}{cccccc}
\hline \multirow{2}{*}{ No } & $2 \Theta(\mathrm{deg})$ & $\mathrm{d}(\AA)$ & \multicolumn{2}{c}{ FWHM } & Ukuran Kristal (nm) \\
\cline { 4 - 5 } & & & $\mathrm{deg}$ & $\mathrm{rad}$ & \\
\hline 1. & 37,8346 & 2,37598 & 0,1831 & 0,003194 & 50,00548 \\
2. & 44,0706 & 2,05316 & 0,1767 & 0,003082 & 52,88069 \\
3. & 64,4428 & 1,44469 & 0,1994 & 0,003478 & 51,34508 \\
4. & 7,5543 & 1,22560 & 0,2403 & 0,004192 & 46,23518 \\
\hline
\end{tabular}

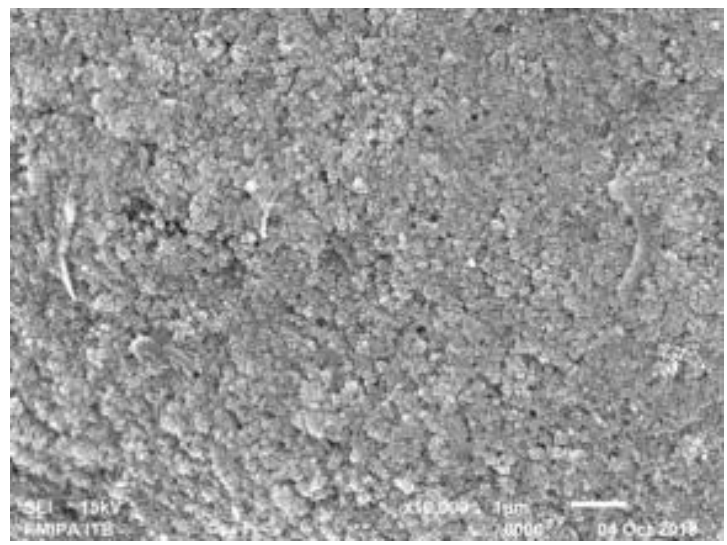

(a)

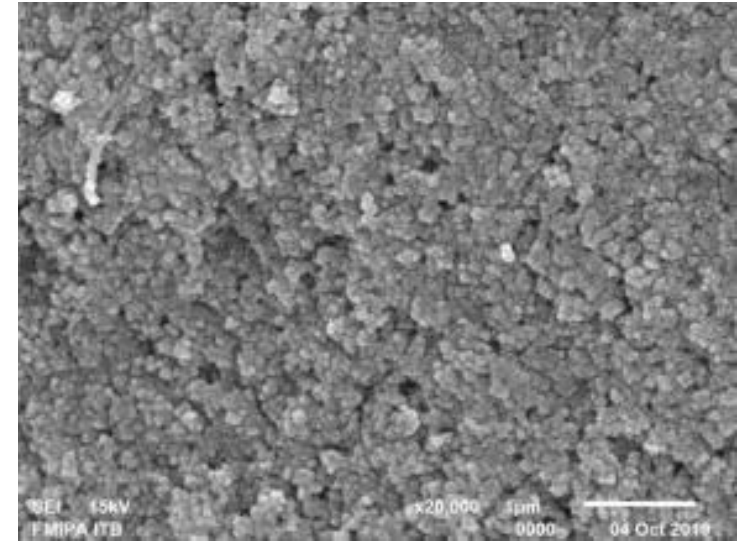

(b)

Gambar 6. Morfologi nanopartikel perak pada perbesaran 10.000x (a) dan 20.000x (b)

\section{Morfologi Nanopartikel Perak dengan SEM}

Analisis SEM bertujuan untuk menunjukkan morfologi partikel. Pembesaran gambar nanopartikel perak dilakukan pada skala 10.000x, dan 20.000x. Hasil analisis disajikan pada Gambar 6a dan 6b.

Morfologi nanopartikel menunjukkan bahwa nanopartikel memiliki bentuk dan ukuran yang beragam. Masakke et al. (2015) dan Taba et al. (2019) menjelaskan bahwa ukuran yang beragam diakibatkan oleh efek agregasi nanopartikel dan memiliki partikel yang tidak seragam.

\section{KESIMPULAN}

Berdasarkan hasil penelitian dapat disimpulkan bahwa ekstrak daun eceng gondok
(Eichornia Crassipes) mampu berfungsi sebagai bioreduktor dalam proses sintesis nanopartikel perak. Sintesis nanopartikel dengan ekstrak eceng gondok (Eichornia Crassipes) menghasilkan nanopartikel perak berwarna kuning kecoklatan yang memiliki panjang gelombang 435-441 nm berbentuk bulat tidak seragam dan memiliki diameter partikel rata-rata $93,2 \mathrm{~nm}$ dengan ratarata ukuran kristal 50,11 $\mathrm{nm}$.

\section{DAFTAR PUSTAKA}

Abdullah, M., Virgus, Y., Nirmin, \& Khairurrijal. (2008). Review: Sintesis Nanomaterial. Jurnal Nanosains \& Nanoteknologi, 1(2): 33-57.

Ariyanta, H. A. (2016). PREPARASI Nanopartikel Perak Dengan Metode 
Reduksi dan Aplikasinya Sebagai Antibakteri Penyebab Luka Infeksi. Media Kesehatan Masyarakat Indonesia, 10(1): 36-42.

https://doi.org/10.30597/mkmi.v10i1.477

Chandran, S. P., Chaudhary, M., Pasricha, R., Ahmad, A., \& Sastry, M. (2006). Synthesis of Gold Nanotriangles and Silver Nanoparticles Using Aloe vera Plant Extract. Biotechnology Progress, 22(2): 577-583.

https://doi.org/10.1021/bp0501423

Leela, A., \& Vivekanandan, M. (2008). Tapping The Unexploited Plant Resources for The Synthesis of Silver Nanoparticles. African Journal Of Biotecnology, 7(17): 31623165.

Marlinda, Zakir, M., \& Hariani, N. (2016). Sintesis Nanopartikel Perak Menggunakan Bioreduktor Ekstrak Daun Paliasa (Kleinhovia hospita Linn.) Dan Potensinya Sebagai Tabir Surya. (diunduh di https://www.semanticscholar.org/paper/SI NTESIS-NANOPARTIKEL-PERAKMENGGUNAKAN-BIOREDUKTOR-MarlindaZakir/44b10df24c3b09d98a8e712b14dcd 79fdfbad1e3 pada tanggal 21 Juli 2020).

Masakke, Y., Rasyid, M., \& Sulfikar. (2015). Biosintesis Partikel-nano Perak Menggunakan Ekstrak Metanol Daun Manggis (Garcinia mangostana L.). Jurnal Sainsmat, 4(1): 28-41.

Matutu, J. M., Maming, \& Taba, P. (2016). Sintesis Nanopartikel Perak Dengan Metode Reduksi Menggunakan Buah Merah (Pandanus conoideus) Sebagai Bioreduktor. (diunduh di https://pdfs.semanticscholar.org/76f8/fb46 e35a6b1c311b35140f39d39a3ab7509a.p df pada tanggal 14 Februari 2020).

Mustari, S., Suryaningsih, S., \& Kartawidjaja, M. (2017). Analisa Sifat Adsorpsi Logam
Berat Pada Eceng Gondok Dalam Pengelolaan Air Limbah Elektroplating. Jurnal Material dan Energi Indonesia, 7(1): 44-48.

Taba, P., Paramitha, N., \& Kasim, S. (2019). Sintesis Nanopartikel Perak Menggunakan Ekstrak Daun Salam (Syzygium polyanthum) Sebagai Bioreduktor Dan Uji Aktivitasnya Sebagai Antioksidan. Indo. J. Chem. Res., 7(1): 51-60.

Wijaya, D., Yanti, P. P., A, R. S., Rizal, M., \& A, R. S. (2015). Screening Fitokimia dan Aktivitas Antioksidan Daun Eceng Gondok (Eichhornia crassipes). Jurnal Kimia VALENSI, 1(1): 65-69. https://doi.org/10.15408/jkv.v0i0.4965

Yanti, W. R. O., \& Astuti, A. (2018). Sintesis Nanokristal Perak Menggunakan Ekstrak Kulit Buah Manggis (Garcinia mangostana L.). Jurnal Fisika Unand, 7(3): 286-291. https://doi.org/10.25077/jfu.7.3.286291.2018 